\title{
Helicopter Evacuation of Trauma Victims in Los Angeles: Does It Improve Survival? Reply to Letter
}

\author{
Peep Talving • Galinos Barmparas • \\ Lydia Lam · Kenji Inaba • Demetrios Demetriades
}

Published online: 3 March 2010

(C) Société Internationale de Chirurgie 2010

We thank Dr. Hardcastle for his interest in and careful review of our article on the use of helicopters for transporting trauma victims in the metropolitan Los Angeles area [1]. In his letter [2], Dr. Hardcastle expressed concerns regarding the validity of our results which detected no difference in mortality between helicopter- and ground-transported patients for whom the transportation time exceeded $30 \mathrm{~min}$. Dr. Hardcastle based these concerns on the fact that airlifted patients were more severely injured than their groundtransported counterparts, suggesting that this may have introduced bias into our results. Dr. Hardcastle proposed a comparison of the observed mortality with the predicted mortality to reveal a possible clinically significant difference in survival. Control of bias in retrospective studies may be challenging. However, the methodology that Dr. Hardcastle proposed to control for bias in our study will not improve the validity of the obtained results. To attain the predicted mortality we would need to utilize one of the scoring systems available, such as the revised trauma score (RTS) [3] or the trauma and injury severity score (TRISS) [4]. The use of these scores, however, has proven to be of limited value in predicting outcomes $[5,6]$. In addition, we do not share the view that we would solve the issue of identifying clinically significant difference by comparing the actual mortality with the predicted mortality obtained from such scoring systems.

\footnotetext{
P. Talving $(\bowtie) \cdot$ G. Barmparas · L. Lam · K. Inaba .

D. Demetriades

LAC + USC Medical Center, Division of Trauma Surgery and Surgical Critical Care, University of Southern California, 1200 North State Street, IPT, Room C4E100,

Los Angeles, CA 90033, USA

e-mail: ptalving@gmail.com

G. Barmparas

e-mail: galinos.barbaras@gmail.com
}

Nevertheless, in our analysis we used the vast majority of the variables upon which the calculation of these scores is based, such as GCS, blood pressure, and ISS. In addition, we used multivariable logistic regression to control for possible confounders. Therefore, it is expected that there will not be any difference between the compared groups with respect to observed and predicted mortality.

Nonetheless, we agree that a survival benefit for patients transported by helicopter may not have been clarified without any doubt in our studied population. The adjusted odds ratio $(95 \% \mathrm{CI})$ of $0.72(0.22,2.35)$, depending on what we define as clinically significant difference, may cross the zone of clinical indifference and may therefore indicate that our results ought to be interpreted cautiously. This issue can be solved only by increasing the sample size.

We thank Dr. Hardcastle again for his insightful comments and we hope that we have addressed his concerns.

\section{References}

1. Talving P, Teixeira PG, Barmparas G et al (2009) Helicopter evacuation of trauma victims in Los Angeles: does it improve survival? World J Surg 33(11):2469-2476

2. Hardcastle T (2010) RE: Helicopter evacuation of trauma victims in Los Angeles: does it improve survival? World J Surg 34. doi: 10.1007/s00268-009-0386-7

3. Champion HR, Sacco WJ, Copes WS et al (1989) A revision of the Trauma Score. J Trauma 29(5):623-629

4. Boyd CR, Tolson MA, Copes WS (1987) Evaluating trauma care: the TRISS method. Trauma Score and the Injury Severity Score. J Trauma 27(4):370-378

5. Gabbe BJ, Cameron PA, Wolfe R (2004) TRISS: does it get better than this? Acad Emerg Med 11(2):181-186

6. Demetriades D, Chan LS, Velmahos G et al (1998) TRISS methodology in trauma: the need for alternatives. Br J Surg 85(3): 379-384 